\title{
Karpal Tünel Sendromu
}

\author{
Carpal Tunnel Syndrome
}

Buket Tuğan Yıldız

Karpal tünel sendromu (KTS) median sinirin bilekte tuzak nöropatisidir. KTS' nin patogenezinde en sık görülen, karpal tünel içi basıncın artmasıdır. Kalınlașmanın nedeni ise çok açık değildir. Kollajen doku hastalıkları, diabetes mellitus, șișmanlık, gebelik, miksödem, tümörler, ön kol, bilek veya ele akut yada kronik travma KTS ile birlikte görülen bazı hastalık ve durumlardır. Yine de; hastaların çoğunda altta yatan bir neden bulunmaz ve bu tabloya idiyopatik KTS denir. Direkt travma olmadığı sürece KTS semptomlarının bașlangıcı nokturnal ve sinsidir. Bașlangıçta hastalar elde parestezilerden ve dizestezilerden rahatsızdırlar. KTS tanıSı klinik olarak konur. Tanıdan șüphelenilen durumlarda, cerrahi öncesi elektrofizyolojik yöntemlerden yararlanılabilir. Tedavide gece ateli, non-steroid antienflamatuar ilaçlar, ultrason, elektiriksel sinir uyarısı gibi yöntemler kullanılabilir. Cerrahi dekompresyon ağrı ve uyușmanın dayanılmaz olduğu durumlarda veya motor kayıp varsa düșünülmelidir.

\section{Anahtar Sözcükler: Karpal Tünel Sendromu, Gece Parestezisi, Median Sinir}

Carpal tunnel syndrome(CTS) is an entrapment neuropathy of the median nerve at the wrist. CTS's the most common pathogenesis is thickening flexor retinaculum. The reason of thickening is unclear. Collagen tissue disease, diabetes mellitus, obesite, pregnancy, myxedema, tumors, acute or chronic trauma of forearm, wrist or hand are common things and illness which accompanies with CTS. Nevertheless; in the most patient the cause of CTS is often not apparent and this is called idiopatic carpal tunnel syndrome. Unless associated with direct trauma, the onset of symptoms of CTS is usually nocturnal and insidious. İnitially, patients suffers paresthesia and dysesthesia in the hand. The diagnosis of CTS based on clinic features. If the diagnosis is uncertain and before surgery, electrophysiologic studies may be useful. In the treatment hand splints, non-steroid antiinflammatory drugs, ultrasound, electrical nerve stimullation may be useful. If the pain and dysesthesia is severe surgery decompresion operation may be done.

Key Words: Carpal Tunnel Syndrome, Nocturnal Paresthesia, Median Nerve

Karpal tünel sendromu (KTS), median sinirin elde karpal kemikler ile transvers ligaman arasından geçişi sırasında sıkışmasına bağlı olarak ortaya ç1kan klinik tablodur. KTS en yayg1n tuzak nöropatisidir (1-4).

Direk travma olmadiğı sürece semptomların başlangıcı nokturnal ve sinsidir. Karakteristik başlangıç semptomu geceleri uykudan uyandıran elde uyuşmadır. $\mathrm{Bu}$ dönemde muhtemelen elin uykudayken bilekten fleksiyonda kalması nedeniyle kanal içerisindeki basıncın kritik düzeye ulaşması sinirde fokal iskemiye ve bunun sonucunda da parestezilere yol açmaktadır (5). Karpal tüneldeki kitle artıșı sürdükçe median sinir el nötral pozisyondayken de sıkışmaya başlar ve bu dönemde semptomlar sürekli hale gelir. Hasta özellikle tek elle yapılan işlerde beceriksiz olduğunu fark eder. Örneğin; çaydanlık elinden düşecek gibi olur veya tornavida kullanmakta zorlanmaya başlar. Parestezi ve dizesteziler gece uyandırmaya devam ettiği gibi, artık gündüzleri de mevcuttur. İleri dönemde motor aksonal harabiyet de tabloya eklenerek tenar atrofiye yol açar (6).

KTS ilk defa 1854 yilında distal radius fraktürlü bir olguda Sir James Paget tarafindan tanımlanmıştır (7-11). 1913'te Marie ve Foix 80 yaşında tenar atrofili olguda, median sinirin uzun dönem kompresyonu sonucu gelişen patolojik değişiklikleri tanımlamıştır (12, 13). 1933 yllında, 
median siniri posttravmatik osteoartritik osteofitlerle komprese olan bir olguda Learmonth median sinirin ilk cerrahi dekompresyonunu tanımlamıştır (14). 1947 yılında Brain, Wright ve Wilkinson cerrahi tedavi ile düzelen tipik klinik semptomlu hasta serisinde "karpal tünel sendromu" terimini kullanmışlardır (15).

\section{Patogenez ve Etyoloji}

Karpal tünel denen ve sekiz karpal kemik ile fleksör retinakulumun meydana getirdiği fibroosseöz yapıdaki boşluğun azalması veya sinirin bası etkisine duyarlılığının artması sendroma yol açabilir. Buna neden olan klinik durumlar vardir. Ancak hiçbir hastalık bulunmaksızın da, sinovial membranlar ve diğer yapılardaki normal dejeneratif değişikliklerin, konjenital olarak dar olan tünelde sinirin sıkışmasına yol açması mümkündür (7). Gündüzleri bilekte ekstansiyon ve fleksiyona yol açan uğraş ve meslekler ağr1 ve parestezileri artırır. En çok bulaşık yıkama, kitap veya gazeteyi uzun süre bilekler fleksiyonda iken tutma, çekiç sallama, boya yapma veya uzun süre bir arabanin direksiyonunu kullanma, örgü örmelerde artar (16). KTS' nin patogenezinde en sik görülen, fleksör retinakulumun kalınlaşmasıdır. Kalınlaşmanın nedeni ise çok açık değildir (17). Kollajen doku hastalıkları (romatoid artrit, sistemik lupus eritematosus, skleroderma, polimyaljia romatika, eozinofilik fasiitis), nonspesifik tenosinovit, tetik parmak, diabetes mellitus, şişmanlık, gebelik, östrojen ve oral kontraseptif kullanım, Akromegali, hiperparatiroidizm, miksödem, amiloidoz, tümörler (gangliomalar, lipomalar...), ön kol, bilek veya ele akut yada kronik travma, tekrarlayıc1 hareketler KTS ile birlikte görülen bazı hastalık ve durumlardır. Yine de; hastaların çoğunda altta yatan bir neden bulunmaz ve bu tabloya idiyopatik karpal tünel sendromu denir (18).

\section{Klinik}

Direkt travma olmadiğ1 sürece KTS semptomlarının başlangıcı nokturnal ve sinsidir. Hastalarda parestezi, dizestezi gibi pozitif veya hipoestezi gibi negatif duyusal yakınmalar olabilir. Başlangıçta hastalar elde parestezilerden ve dizestezilerden rahatsizdirlar (19,20). Daha seyrek olmakla birlikte, KTS'de elde ve hatta bazen tüm kola ve omuza yayılabilen ağr1 da görülebilir. Parmakların şişlikten dolayı kullanılamadığına dair subjektif bir şikayet olabilir, ancak muayenede ödem varsa dahi minimaldir. Aşırı terleme ve hafif dereceli ödem KTS'de olduğu bilinen vazomotor bozukluğa bağlıdır. Özellikle soğuğa maruziyetle parmaklarda renk değişikliği tarif edilebilir (21). Nokturnal ağrı ve uyuşma hastayı birkaç saatlik uykudan sonra uyandırmaya başlar. Kolu yataktan sarkitmayla, sallamayla, ovuşturmayla iyileşme görülebilir, fakat semptomlar artarsa hasta yataktan kalkar ve semptomlar düzelene kadar yürür (6). Noktürnal ağrilarla uyanma ve eli sallayarak bu ağr1 ve parestezilerin kaybolması veya hafiflemesi $\% 93$ oranda taniya yardımcı bulunmuştur. Aslında bu sırada hasta serçe parmağına dokunsa uyuşuk olmadığını fark edebilir. Bazen de birey sabah kalktığında ellerini ağrilı ve odun gibi sert hisseder. Ama bu dönemlerde objektif klinik bulgu bulunamayabilir. KTS ilerledikçe noktürnal ağrı ve parestezilerin sikliğ1 $\operatorname{artar}(22)$. Bu evrede epizodik uyuşma gün boyu devam eder (6). Daha sonra duysal yakinmalar objektif duysal bozukluklara dönüşür. El parmaklarında, en çok 2 . ve 3 . Parmakta dizestezik yakınmalar ortaya ç1kar (16). Abduktor pollicis brevis veya opponens pollisis kaslarinda önce kuvvetsizlik daha ilerde tenar kaslarda atrofi ve buna bağlı çökme meydana gelir(6). Tinel, Phalen ve ters Phalen işaretleri olabilir, ancak sanıldığından daha nadir pozitiftir. Tinel testinin negatifliği daha sıktır. Phalen testi ise yalnızca 1 dakika bekletildiği için negatif çıabilir. Oysa hastanın eli gece boyu fleksiyonda kalmaktadir (23). Bütün muayene bulguları normal bile olsa gece olan, eli sallamakla geçen uyuşmaların yanı sıra bu esnada serçe parmağının uyuşuk olmamas1 tanı koydurucudur (22).

\section{Tanı}

Karpal tünel sendromu tanısı klinik olarak konur ve genellikle sinir iletim çalışmalarından da yararlanılır (4, 24). Tanıdan şüphelenilen durumlarda, cerrahi öncesi, ek bir nöropatinin ekartasyonu için elektrofizyolojik yöntemlerden yararlanılabilir. Her ne kadar ENMG, KTS tanısındaki altın standart olsa da iletim çalışmalarındaki duyarlılık hiçbir zaman \%100 olmamaktadir (25). Semptomları şiddetli olmayan erken evredeki hastalarda elektofizyolojik testler normal olabilir. Karpal tünel sendromunun elektrofizyolojik tanısında median sinir duyusal ve motor iletim çalışmaları ve distal motor latans en sik kullanilan yöntemlerdir. Duyusal iletim çalışmaları, motor iletim çalışmalarından daha duyarlıdır (26, 27).

\section{Tedavi}

KTS'nin tedavisi iki unsurludur: Altta yatan hastalığın tedavisi ve KTS'ye yönelik tedavi. İdiyopatik KTS'de -ki hastaların büyük çoğunluğu böylediröncelikli olarak konservatif tedaviler denenmelidir. Gece uyanmalarını önlemek üzere, hastaya sadece geceleri kullanması için bilek ateli verilir. Bu atel eli bilekten 15 derece dorsifleksiyonda sabitler ve gece boyunca istemsiz bilek fleksiyonlarını önleyerek hastanın semptomlarını rahatlatır. Semptomları gidermek için non-steroid antienflamatuar ilaçların yanısıra ultrason ve elektriksel sinir uyarısı gibi fizik tedavi yöntemleri kullanılabilir. Cerrahi dekompresyon ağr1 ve uyuşmanın dayanılmaz olduğu durumlarda veya motor kayıp varsa düşünülmelidir. Açık ya da endoskopik dekompresyon cerrahisinin başarısı yüksektir ve komplikasyonlar seyrek veya hafiftir. Yetersiz serbestleştirme yüzünden nadiren nüks görülür (16). 


\section{KAYNAKLAR}

1. Chang M.-H., Wei S-J., Chiang H.-L. et all. Comparison of motor conduction techniques in the diagnosis of carpal tunnel syndrome. Neurology 2002; 58: 1603-1607

2. American Academy of Electrodiagnostic Medicine Quality Assurance Committee. Literature review of the usefulness of nerve conduction studies and electromyography for the evaluation of patients with carpal tunnel syndrome. Muscle Nerve 1993; 16: 1392-1414

3. Stevens IC. The electrodiagnosis of carpal tunnel syndrome. Muscle Nerve 1997; 20: 1477-1486

4. Esther Vögelin, Thomas Meszaros, Franziska Schöni et al. Sonographic wrist measurements and detection of anatomical features in carpal tunnel syndrome. The scientific World journal.2014; 657906: 1-6

5. Robert A. Werner, Michael Andary. Carpal tunnel syndrome: pathophysiology and clinical neurophysiology. Clinical Neurophysiology 2002; 113: 1373-1381

6. Bleecker Margit L, Agnew Jacqueline. New techniques for the diagnosis of carpal tunnel syndrome. Scand J Work Environ Health. 1987; 13: 385-388

7. Stewart JD. Compression and entrapment neuropaties. In: Peripheral Neuropathy, vol.2. 3rd edition. Ed. PJ Dyck and K Thomas. Saunders Company. Philadelphia, London, Toronto, Montreal, Sydney, Tokyo. 1993: 961-979.

8. Lee D, van Holsbeeck MT, Janevski PK et al. Diagnosis of carpal tunnel syndrome: Ultrasound versus electromyography. Radiol Clin North Am. 1999; 37: 859-872
9. Amadio P.C. Historical Review: The Mayo Clin and carpal tunnel syndrome. Mayo Clin Proc 1992; 67: 42-48

10. Pfeffer GB, Gelberman RH, Boyers JH. The History of carpal tunnel syndrome. J Hand Surg Br. 1988: 13; 28-34

11. Bienek T, Kusz D, Cielinski L. Peripheral nerve compression neuropathy after fractures of distal radius. J Hand Surg. 2006: 31; 256-260

12. Marie P, Foix C. Atrophie isolee de l'eminence thenar d'origine nevritique Role du ligament annulaire Role du ligament annulaiere anter ieur de carpe dans la pathogenic de la lesion. Rev Neurol Paris. 1913: 26; 647-649

13. Rengahary S. Entrapment neuropathies, Wilkins R. (Eds.), Neurosurgery, Newyork, Mc. Graw Hill Back Company: 1985: 1771-1777

14. Tindall S.: Chronic injuries of peripheral nerves by entrapment, in Youmans JR (Ed.): Neurological Surgery, Philadelphia, Saunders W.B. : pp. 1990; 2511-2524:

15. Donwart BB. Carpal tunnel syndrome: a review. Semin Arthritis Rheum. 1984: $14 ; 134-140$

16. Bagatur AE. Karpal tünel sendromu cerrahisinde başarısızlık nedenleri ve revizyon sonuçları. Acta Orthop. Traumatol. Tur. 2002; 36: 346-353

17. Kimura J, Machida M, Kimura A: Median Neuropathies (Ch.4). In: Clinical Electromyography. Edited by WF Brown and CF Bolton, Boston, Butterworths, 1987

18. Harrison MJG: Lack of evidence of generalized sensory neuropathy in patients with carpal tunnel syndrome. J. Neurol Neurosurg Psychiatry 1978; 41: 957-959
19. Robert A. Werner, Michael Andary. Carpal tunnel syndrome: pathophysiology and clinical neurophysiology. Clinical Neurophysiology 2002; 113: 1373-1381

20. Carlos H. Fernandes, Lia M. Meirelles, Jorge Raduan. Carpal tunnel syndrome with thenar atrophy: evaluation of the pinch and grip strength in patients undergoing surgical treatment. Hand. 2013; 8: 60-63

21. Aminoff MJ. Involvement of peripheral vasomotor fibres in Carpal Tunnel Syndrome. J Neurol Neurol Neurosurg Psychiatry 1979; 42: 649-655

22. Ertekin C. Santral ve periferik EMG. İzmir; 2006:416-419

23. Gelmars H. The significance of Tinel's sign in the diagnosis of carpal tunnel syndrome. Acta Neurochir 1979; 49: 255 258

24. Nai-Wen Tsai, Lian-Hui Lee, Chi-Ren Huang et al. The diagnostic value of ultrasonography in carpal tunnel syndrome: a comparison between diabetic and non- diabetic patient. BMC neurology. 2013; 13:65

25. Cioni R, Pasero S, Paradiso C, et al. Diagnostic specificity of sensory and motor nerve conduction variables in early detection of carpal tunnel syndrome. J Neurol 1989; 236: 208-231

26. AAEM, AAN, AAPMR: Practice parameter for electrodiagnostic studies in carpal tunnel syndrome: summary statement. Muscle Nerve. 1993; 16: 13901391

27. Padua Luca, Monaco Mauro Lo, Valente Enza Maria, et al. A useful electrophysiologic parameter for diagnosis of carpal tunnel syndrome. Muscle Nerve. 1996; 19: 48-53 
